\title{
Construcciones con adverbios relativos de lugar en distintas lenguas romances: español, francés e italiano. Estudio comparativo en tres ediciones actuales de El Quijote
}

\author{
Míriam González Santolalla ${ }^{1}$
}

Recibido: 13 de septiembre de 2017 / Aceptado: 19 de marzo de 2018

Resumen. En este trabajo estudiamos el funcionamiento de los adverbios relativos de lugar en distintas lenguas romances, concretamente, en español (donde), francés (où) e italiano (dove). A partir del origen latino común de estos términos, mostraremos su evolución hasta la actualidad, y pasaremos después a analizar las construcciones en que intervienen en cada lengua. Se identifican varios procedimientos para la expresión de los matices locativos -la ubicación, la procedencia, la dirección o el trayecto- y no locativos - los sentidos temporal, consecutivo o final, entre otros- basados, principalmente, en la anteposición de preposiciones o en la existencia de diferentes adverbios asociados a determinados valores. El estudio llevado a cabo en este trabajo nos permitirá conocer en qué medida los procedimientos descritos en las gramáticas descriptivas y normativas consultadas recogen el funcionamiento de estos adverbios en una obra literaria traducida al español, francés e italiano actuales.

Palabras clave: adverbios relativos; donde, où, dove; ubicación; procedencia; dirección; trayecto.

\section{[en] Constructions with relative adverbs of place in different Romance languages: Spanish, French and Italian. Comparative study in three current editions of El Quijote}

\begin{abstract}
In this paper we aim to study how relative adverbs of place function in different Romance languages, such as Spanish (donde), French (où) and Italian (dove). With the common Latin origin of these terms as a starting point, we will aim to show their evolution until now and we will analyze the grammatical workings of the constructions in which they intervene. Several procedures are identified for the expression of locative details -location, origin, direction or path-and not locative - temporal, consecutive or final senses, among others- based, mainly, on the placement of prepositions before the adverb or the existence of different adverbs associated with certain values. The study carried out will allow us to know if the procedures described in the reviewed descriptive and normative grammars reflect the functioning of these relative adverbs in a literary work translated into current Spanish, French and Italian.
\end{abstract}

Key words: relative adverbs; donde, où, dove; location; origin; direction; path.

Sumario. 1. Introducción. 2. Corpus y metodología. 3. Estudio de los adverbios relativos de lugar en la primera parte de la obra El ingenioso hidalgo don Quijote de la Mancha. 3.1. Frecuencia de uso. 3.2. Expresiones alternativas o equifuncionales. 3.2.1. Cruces existentes en español entre donde y a donde/ adonde. 3.2.2. Posible alternancia entre las formas d'où y dont. 3.2.3. Uso y alternancia entre las formas

Universidad Nacional de Educación a Distancia (UNED)

mgsantolalla@gmail.com 
dove - ove y donde - onde. 3.3. Extensión hacia valores no locativos. 4. Conclusiones. 5. Referencias bibliográficas

Cómo citar: González Santolalla, M. (2018). Construcciones con adverbios relativos de lugar en distintas lenguas romances: español, francés e italiano. Estudio comparativo en tres ediciones actuales de El Quijote, en Revista de Filología Románica 35, 79-101.

\section{Introducción}

Los adverbios relativos de lugar se integran en un grupo gramatical ampliamente tratado por gramáticos de todas las épocas: los relativos. Estos, a diferencia de los interrogativos y exclamativos -con quienes comparten rasgos morfológicos- tienen antecedente en la oración, explícito o implícito; presentan un carácter átono ${ }^{2}$ y no pueden introducir actos verbales ${ }^{3}$ (Nueva Gramática de la Lengua Española ${ }^{4}$ 2009: $\S 22.1 \mathrm{a}, 22.2 \mathrm{a})$. En las tres lenguas estudiadas en este trabajo, estos adverbios son donde (esp.), où (fr.) y dove (it.). Desde una perspectiva morfológica, los adverbios relativos difieren de otros relativos -pronombres y determinantes: quien, que, cuyo, el cual, en español (NGLE 2009: § 22.4-5); qui, que, quoi, dont, en francés (Cantera y De Vicente 2003: 22); chi, che, cui, il quale, en italiano (Dardano y Trifone 1985: 178) - en que los primeros carecen de flexión de género y número, a diferencia de la mayoría de los segundos. En el plano sintáctico, los adverbios relativos funcionan como modificadores del grupo verbal, mientras que los relativos no adverbiales pueden ejercer otras funciones dentro del predicado, pueden ser también sujetos e incluso pueden funcionar como determinantes (esta última función es exclusiva de cuyo, dont y cui). A nivel semántico, los adverbios relativos que analizamos introducen una circunstancia de lugar (NGLE 2009: § 22.1d, 22.1f, 22.11).

Los adverbios relativos de lugar de cada una de las tres lenguas estudiadas son herederos de cuatro adverbios relativos latinos que se utilizaban para señalar distintas circunstancias de lugar:

a) ŬBI ('donde', 'en donde'), con valor de ubicación: exsilium ibi esse putat, ubi virtuti non sit locus (Cicerón Mil.): 'Piensa que el exilio está allí donde no hay lugar para el valor', ap. Pinkster (1995: 153).

b) ǓNDE ('de donde'), con valor de procedencia: Saguntum vestri circunsedent exercitus, unde arcentur foedere (Tito Livio Ab urbe condita, libro XXI): 'Vuestros ejércitos asedian Sagunto, de donde son rechazados en virtud de un tratado', ap. Calero Calero (2003: 187).

\footnotetext{
Algunos hablantes pronuncian y escriben los relativos como palabras tónicas en determinadas construcciones: No hallé dónde dormir. Sin embargo, esta marca gráfica no convierte a los relativos en interrogativos (NGLE 2009: § 26.12i). La posibilidad de articular estos nexos como átonos o tónicos aparece en subordinadas relativas sin antecedente expreso cuando este antecedente implícito es indefinido y de carácter inespecífico, fundamentalmente, en oraciones sin antecedente dependientes de verbos como hacer, tener, buscar, encontrar, necesitar, etc. (Ortografia de la lengua española 2010: \$3.4.3.2.3.a): No tiene donde hospedarse.

3 Los exclamativos e interrogativos pueden iniciar actos verbales: ¿Dónde estás?, a diferencia de los relativos: *donde puedas > Déjalo donde puedas (el relativo inicia un periodo oracional dependiente del verbo deja).

4 En adelante, $N G L E$.
} 
c) QUO ('a donde'), con valor direccional: Eo quo Labienum miserat contendit: 'Se dirigió allí a donde había enviado a Labieno' (Julio César La guerra de las Galias, ap. Rubio 1995: 60).

d) QUA ('por donde'), con valor de trayecto: Prope siet aut mare aut amnis, qua naues ambulant (Catón De agricultura, ap. Sánchez Salor 1993: 220): 'Que esté cerca del mar o el río por donde circulan los barcos'.

Los dos últimos adverbios desaparecen sin dejar rastro en español, francés e italiano; cada una de estas lenguas opta por una o dos de las formas relativas latinas

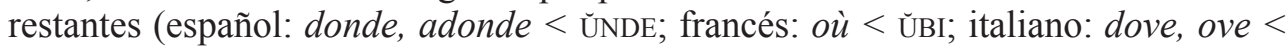
ŬBI, donde, onde < ŬNDE) y muestra en la actualidad resultados diferentes en función de distintos cambios fonéticos, categoriales y sintácticos. En otras lenguas romances, los adverbios proceden principalmente de ǓNDE: catalán, on < ǓNDE; gallego, onde $<$ ŬNDE; portugués, onde $<$ ŬNDE y rumano, unde < ŬNDE. Así pues, podríamos establecer una división entre las lenguas que presentan formas derivadas de ŬBI y aquellas que lo hacen de ǓNDE, puesto que las segundas, a excepción del rumano, se concentran geográficamente en la Península Ibérica.

En este trabajo proponemos un estudio de los adverbios relativos de lugar en español, francés e italiano. Para ello, consideraremos su funcionamiento en una obra literaria del siglo XVII traducida al español, francés e italiano actuales. Estos nexos son susceptibles de expresar determinados valores locativos en presencia o ausencia de preposición y con capacidad de ampliar su referencia locativa para asumir otros valores. Los distintos procedimientos sintácticos y semánticos que cada una de las lenguas estudiadas ha desarrollado en el ámbito de los adverbios relativos de lugar nos conducen a establecer los siguientes objetivos en este trabajo:

a) Conocer los valores locativos y no locativos que expresa el adverbio relativo de lugar principal en español, francés e italiano, tanto en ausencia de preposición como en los casos en que esta precede al adverbio.

b) Reconocer los cruces experimentados por algunas formas equifuncionales en determinados contextos oracionales: donde - a donde/adonde, en español; d'où - dont, en francés; dove - ove y donde - onde, en italiano.

c) Analizar y comparar los valores no locativos expresados en cada lengua por el adverbio relativo de lugar.

\section{Corpus y metodología}

En nuestro estudio consideraremos las siguientes expresiones: en español, donde (y los grupos en que el adverbio se halla precedido de preposición, entre los que hemos encontrado los siguientes: a donde, de donde, desde donde, por donde, hasta donde, hacia donde), adonde y do; en francés, où (junto con los grupos d'où, par où) y dont $t^{5}$; en italiano, dove (además de los grupos di dove, da dove, per dove, verso dove, su dove, a dove), donde y onde $e^{6}$. Se excluyen de este estudio los adverbios interrogativos homónimos.

El corpus estudiado está formado por tres ediciones de la primera parte de la obra El ingenioso hidalgo don Quijote de la Mancha, de Miguel de Cervantes: la

Solo hemos considerado las apariciones del pronombre dont en aquellos casos en que equivale al grupo d'où.

El adverbio ove no se ha documentado en nuestro corpus. 
adaptación al castellano actual de Andrés Trapiello en 2015, la traducción al francés contemporáneo que preparó Aline Schulman en 1997 y la edición italiana del año 2003, basada en la traducción al italiano moderno que Alfredo Giannini realizó en el año $1927^{7}$. Las tres ediciones estudiadas ofrecen una representación del estado actual de cada una de las lenguas objeto de nuestro trabajo, por lo que sirven a nuestra intención de realizar un análisis comparativo desde una perspectiva sincrónica.

Los datos que cada una de las obras ha proporcionado son los siguientes: 394 casos en QUI-ESP, 430 en QUI-FR y 341 en QUI-IT. La extracción se ha realizado de forma manual en la edición francesa y de forma digital en las ediciones en línea consultadas para el español y el italiano. Los ejemplos recogidos se han incluido en una base de datos tripartita que almacena de manera independiente las muestras de cada lengua. A partir de la información contenida en esta base de datos se han obtenido los resultados necesarios para el estudio. Estos datos se han volcado a tablas preparadas en hojas de cálculo (Excel) que nos han permitido elaborar los gráficos que aparecerán en este trabajo.

\subsection{Estudio de los adverbios relativos de lugar en la primera parte de la obra $E \boldsymbol{l}$ ingenioso hidalgo don Quijote de la Mancha.}

Nuestro trabajo se centrará en el análisis de tres parámetros: en primer lugar, analizaremos la frecuencia de uso de las formas estudiadas; a continuación, estudiaremos el reconocimiento de expresiones equifuncionales en idénticos contextos oracionales, para lo cual será necesario atender al tipo de relativa que introducen los adverbios relativos de lugar, la presencia de antecedente en la oración, el tipo de verbos con el que aparecen y el sentido de la construcción; por último, comprobaremos la extensión de estos adverbios hacia valores no locativos.

En cada uno de los siguientes apartados presentaremos, en primer lugar, un breve estado de la cuestión, elaborado a partir de la consulta de gramáticas y diccionarios especializados, y, en segundo lugar, un análisis de nuestro corpus basado en los parámetros que acabamos de plantear. Este análisis buscará, en la medida de lo posible, presentar ejemplos de un mismo pasaje de la obra en los tres idiomas para descubrir las distintas alternativas gramaticales por las que cada lengua puede optar en cada caso.

\subsection{Frecuencia de uso}

En este apartado consideramos la frecuencia relativa (sobre un total de 10.000 palabras) de los adverbios relativos de lugar con sentido de ubicación, procedencia, dirección, trayecto y no locativo en los casos en que dicho adverbio se halla precedido o no de preposición. Nos interesa conocer en qué medida los valores locativos y no locativos pueden transmitirse mediante los adverbios relativos donde, où y dove, y hasta qué punto estos requieren la presencia de una preposición que refuerce la expresión de aquellos sentidos.

Estas ediciones se identificarán en nuestro trabajo con las abreviaturas $Q U I$-ESP, $Q U I$-FR y $Q U I$-IT, respectivamente. 
El español actual cuenta con un único adverbio relativo de lugar, donde (de + onde < ŬNDE) (Corominas-Pascual 1980: s. v. donde; Alvar y Pottier 1983: 331 y Azofra 2009: 169-170). Además del heredero de DE ŬNDE, en la historia del español encontramos varias formas relativas para expresar el lugar. Entre ellas encontramos derivados de ǓBI: $o$, $u$, obe (Menéndez Pidal 1986: 367); derivados de ŬNDE: onde (Corominas-Pascual 1980: s. v. donde) y sus variantes fonéticas ont, ond, on, unde, unt (Cuervo 1953: s. v. donde); y formas creadas a partir de las anteriores: do $(<$ de $+o)$, ado $(<a+d o)$, el propio donde y sus variantes fonéticas don, dont, dond $(<$ de + onde), así como adonde ( $<a+$ donde) (Corominas-Pascual 1980: s. v. donde) $)^{8}$.

El adverbio donde está documentado desde los siglos XII-XIII (Cuervo 1953: s. v. donde) y puede ser precisado mediante la anteposición de diferentes preposiciones (en, de, desde, a, por, hasta, hacia) para señalar la ubicación (1)(2), procedencia (3) (4), dirección (5)-(7) o trayecto (8) ${ }^{9}$ :

(1) $[\ldots]$ de modo que alcance a todos los lugares donde pueda haber un posible demandante [...] (J. R. Díaz Álvarez Geografía del turismo, 1989, CREA).

(2) Colócate ahí en donde se sienta Pedro (ap. Martínez 1989: 161).

(3) Yo podría olvidar [...] los lugares de donde vengo (Labarca Butamalón, ap. Diccionario Panhispánico de Dudas ${ }^{10}$ 2005: s. v. donde).

(4) En una esquina hay una cantina desde donde se oye la algarabía de los clientes (Gallegos Pasado, ap. DPD 2005: s. v. donde).

(5) iba adonde tú sabes (ap. Gili Gaya 1980:313).

(6) Hasta aquel poste es hasta donde debéis correr (ap. Seco 1986: s. v. donde).

(7) Corrimos hacia donde yacía, ya muerto, el ciervo colorado (Guido La invitación, ap. DPD 2005: s. v. donde).

(8) Pues ya puedes largarte por donde has venido (Goytisolo La resaca, ap. Pruñonosa-Tomás 1990: 91).

El adverbio relativo donde expresa el valor de simple ubicación, tras haber perdido el significado de procedencia de su étimo latino. Sin embargo, la anteposición de la preposición en -que resulta redundante en la actualidad y es menos frecuente que la forma simple (NGLE 2009: 22.80; DPD 2005: s. v. donde)-contribuye a que sea más regular el conjunto formado por el adverbio relativo de lugar y las distintas preposiciones que a él se anteponen para la expresión de los matices locativos (Fernández Ramírez 1987: 242-243).

Por su parte, la lengua francesa cuenta en la actualidad con dos formas derivadas de los adverbios relativos de lugar latinos: où (< U ǓBI) y dont (< DE ǓNDE). El adverbio où se registra por primera vez con las formas $u t$ y $o$ a finales del siglo X. En el siglo XI aparecen las formas $u$ y ou -la acentuación de esta última forma procede del siglo XVI para evitar la confusión con la conjunción ou- (Rey 1992: s. v. où). Hoy en día tan solo où mantiene la categoría de adverbio relativo con valor locativo, mientras que dont es un pronombre relativo, a pesar de su invariabilidad, por tener siempre un antecedente de persona, animal o cosa (concreta o abstracta) del que indica la pose-

\footnotetext{
Presentamos en este punto únicamente las formas simples y aquellas que, estando precedidas de preposición, han llegado a soldarse gráficamente en la escritura a excepción de las formas endonde, dedonde y pordonde recogidas por Bello (2002: § 396) por considerarlas de uso minoritario en diacronía.

9 En adelante, en los ejemplos que ofrecemos, se destaca en negrita el adverbio relativo y la preposición que lo acompaña (si es el caso). Por otra parte, cuando se considere oportuno, se subrayarán las palabras que constituyen su antecedente sintáctico, en caso de aparición de este.

10 En adelante, $D P D$.
} 
sión, la causa, la materia, el modo... (Hanse 1983: 342, 338; Cantera y De Vicente 2003: 25$)^{11}$.

En cuanto a los valores locativos expresados por el adverbio où, encontramos la ubicación (9), la dirección (10) y el trayecto (11) (Sandfeld 1965: 1992). Asimismo, où puede estar precedido de distintas preposiciones que maticen su sentido locativo: $d e^{12}$, jusque, par, pour, vers (Hanse 1983: 655):

(9) Je n'ai pas trouvé le tiroir où se trouvent ces photos ( $a p$. Dulin et al. 2006: 170): 'No he encontrado el cajón donde están esas fotos'.

(10) Vienne, où j'aimerais retourner, m'a toujours fascinée (ap. Dulin et al. 2006: 170): 'Viena, adonde me gustaría volver, siempre me ha fascinado'.

(11) Je sais tous les chemins par où je dois passer (Racine, ap. Rey-Debove y Rey 1993: s. v. où): 'Conozco todos los caminos por donde debo ir'.

(12) La ville d'où vous venez ( $a p$. Hanse 1983: 342): 'La ciudad de donde vienes'.

(13) L'endroit jusqu'où il est allé (ap. Rey-Debove y Rey 1993: s. v. où): 'El lugar hasta donde él ha ido'.

(14) Hier soir retour de Paris pour où j'etais parti (Gide, ap. Rey-Devobe y Rey 1993: s. v. où): 'Ayer noche vuelta de París hacia donde había salido'.

(15) Là-bas flottent des drapeaux sur le toits rouges de la gare, vers où court la foule (Colette, ap. Hadermann 1993: 155): 'Allí ondean banderas sobre los tejados rojos de la estación, hacia donde corre la multitud'.

En el caso del italiano, encontramos cuatro adverbios relativos de lugar derivados de precedentes latinos: dove y ove $(<\mathrm{U} \mathrm{BI})$, para los valores de ubicación y dirección, donde y onde (< ǓNDE), con sentido de procedencia (Vocabolario della Lingua Italiana Treccani ${ }^{13}$ 1986: s. v. dove, ove, donde, onde). En la actualidad, el principal adverbio relativo de lugar en italiano es dove ( $<$ DE ǓBI) (Serianni 1995: 54), mientras que ove, donde y onde quedan restringidos al ámbito literario (Dardano y Trifone 1985: 179; Tekavčić 1980: 411):

(16) il paese dove sono nato (ap. Dardano y Trifone 1985: 179): 'el país donde he nacido'.

Este adverbio puede expresar diversos valores locativos en función de la preposición que lo preceda. De esta manera, las preposiciones di y da se anteponen a dove para transmitir el sentido de la procedencia -dove ya fue reforzado etimológicamente mediante la preposición de para sugerir la procedencia-: di dove, da dove (Battaglia 1974: 224) con el consiguiente matiz de salida (di dove) o alejamiento ( $d a$ dove) asociado a cada forma, aunque en ocasiones alternan su uso como variantes estilísticas o diatópicas (Treccani 1986: s. v. dove):

(17) ci spostammo da dove eravamo (ap. Dizionario della Lingua Italiana 2011: s. v. dove): 'nos movimos de donde estábamos'.

(18) Ero uscito a cercare compagnia, non avevo idea di dove andare (Carriera di un criminale, Maria Teresa de Carolis 2014: 12): 'Había salido a buscar compañía, no tenía ni idea de dónde irr ${ }^{14}$.

11 Dont equivale al español cuyo/a/os/as o a los grupos de quien/del que/de la que/de los que/de las que/de lo que y de los cuales/de las cuales (Cantera y De Vicente 2003: 25).

12 Más adelante comentaremos los límites y confluencias existentes entre las formas d'où y dont (vid. infra).

13 En adelante, Treccani.

14 Aunque este ejemplo presente un adverbio interrogativo en lugar de uno relativo, nos muestra con claridad de qué modo la presencia de la preposición condiciona y modifica el matiz locativo expresado por dicho elemento. 
Otra preposición con que puede aparecer el adverbio dove es per (Treccani 1986, s. v. dove):

(19) sei passato per dove sono passato io (ap. Dizionari Garzanti Linguistica 2017: s. v. dove): 'Has pasado por el mismo sitio por donde he pasado yo'.

Para contrastar la información recogida en las gramáticas consultadas con los datos que obtenemos a partir del estudio de nuestro corpus, hemos preparado una tabla de frecuencias con los datos del corpus (vid. infra, Tabla 1), en la que observamos que el español es el idioma con mayor presencia de grupos formados por preposición + adverbio relativo de lugar en la expresión de valores locativos y no locativos: para cuatro de los cinco sentidos estudiados (procedencia, dirección, trayecto y no locativo) es mayor el número de ejemplos en que la preposición precede al adverbio que el número de ejemplos en que aparece solo el adverbio relativo.

En cambio, para el francés hallamos una clara preferencia de las construcciones sin preposición en la mayoría de los valores estudiados, a excepción del sentido de procedencia, en el que los ejemplos donde el adverbio où queda precedido de preposición superan a aquellos en los que el adverbio aparece en solitario.

El italiano, por su parte, se halla en una situación intermedia en relación al estado de las dos lenguas anteriores, ya que la aparición del adverbio dove sin necesidad de preposición cubre con holgura la expresión de los valores de ubicación, dirección y no locativo, mientras que para los sentidos de procedencia y trayecto resultan más frecuentes las construcciones en las que la preposición precede al adverbio.

\begin{tabular}{|c|c|c|c|c|c|c|c|c|c|c|c|c|}
\hline & \multicolumn{4}{|c|}{ español } & \multicolumn{4}{|c|}{ francés } & \multicolumn{4}{|c|}{ italiano } \\
\hline & \multicolumn{4}{|c|}{$\begin{array}{c}\text { \# palabras } \\
176904\end{array}$} & \multicolumn{4}{|c|}{$\begin{array}{c}\text { \# palabras } \\
182780\end{array}$} & \multicolumn{4}{|c|}{$\begin{array}{c}\text { \# palabras } \\
184339\end{array}$} \\
\hline & $\#$ & $\begin{array}{l}\text { frec. } \\
\text { rel. }\end{array}$ & \# & $\begin{array}{l}\text { frec. } \\
\text { rel. }\end{array}$ & $\#$ & $\begin{array}{l}\text { frec. } \\
\text { rel. }\end{array}$ & \# & $\begin{array}{l}\text { frec. } \\
\text { rel. }\end{array}$ & $\#$ & $\begin{array}{l}\text { frec. } \\
\text { rel. }\end{array}$ & $\#$ & $\begin{array}{l}\text { frec. } \\
\text { rel. }\end{array}$ \\
\hline & \multicolumn{2}{|c|}{ donde } & \multicolumn{2}{|c|}{$\begin{array}{l}\text { prep. }+ \text { don- } \\
d e\end{array}$} & \multicolumn{2}{|l|}{ où } & \multicolumn{2}{|c|}{ prep. + où } & \multicolumn{2}{|l|}{ dove } & \multicolumn{2}{|c|}{ prep. + dove } \\
\hline $\begin{array}{l}\text { ubica- } \\
\text { ción }\end{array}$ & 242 & 13,7 & 4 & 0,2 & 259 & 14,2 & 0 & 0 & 234 & 12,7 & 4 & 0,2 \\
\hline $\begin{array}{l}\text { proce- } \\
\text { dencia }\end{array}$ & 1 & 0,1 & 19 & 1 & 6 & 0,3 & 26 & 1,4 & 2 & 0,1 & 14 & 0,8 \\
\hline $\begin{array}{l}\text { direc- } \\
\text { ción }\end{array}$ & 17 & 1 & $48^{15}$ & 2,7 & 18 & 1 & 1 & 0,1 & 38 & 2,1 & 4 & 0,2 \\
\hline $\begin{array}{l}\mathrm{t} \mathrm{r} \text { a }- \\
\text { yecto }\end{array}$ & 3 & 0,2 & 27 & 1,5 & 4 & 0,2 & 1 & 0,1 & 6 & 0,3 & 12 & 0,7 \\
\hline $\begin{array}{l}\text { no lo- } \\
\text { cativo }\end{array}$ & 7 & 0,4 & 13 & 0,7 & 72 & 3,9 & 2 & 0,1 & 4 & 0,2 & 0 & 0 \\
\hline
\end{tabular}

Tabla 1: Frecuencias adverbios precedidos o no de preposición para sentidos locativos y no locativos

Hemos consideramos en este apartado la documentación del adverbio adonde con valor direccional (41 ejemplos) puesto que, pese a haber finalizado el proceso de univerbación y analizarse en la actualidad como un adverbio relativo de lugar diferente de donde, aún identificamos en su estructura morfológica la preposición que refleja el matiz direccional de dicho adverbio: $a$. 
El sentido de la procedencia ofrece en las tres lenguas estudiadas un mayor número de ejemplos de construcciones precedidas de preposición:

(20) Y para que los veas mejor y distingas, retirémonos a aquella loma que está allí, desde donde se deben de avistar los dos ejércitos. (QUI-ESP).

(21) Et afin que tu puisses les observer à ton aise, retirons-nous sur cette éminence, d'où l'on peut les apercevoir toutes deux. (QUI-FR).

(22) E perché meglio tu li veda e li noti, ritiriamoci su quel monticello che si leva laggiù, di dove si debbono discoprire i due eserciti. (QUI-IT).

Esta presencia mayoritaria de los grupos preposicionales con valor de origen en español, francés e italiano muestra la necesidad de diferenciar gramaticalmente los significados de ubicación y procedencia, al igual que ocurría en latín. La diferencia entre los procedimientos utilizados en latín y las lenguas estudiadas para distinguir los sentidos locativos reside en que el latín optó por el uso de cuatro adverbios para transmitir los sentidos locativos, mientras que en las lenguas romances estudiadas se identifica un único adverbio relativo de lugar precedido de diversas preposiciones.

Por otro lado, el sentido de trayecto depende en español e italiano en mayor medida de construcciones precedidas de preposición (23) y (24), una situación que el francés resuelve con el adverbio où y la presencia de verbos que aluden al movimiento (Cano Aguilar 1981: 83) (25):

(23) [...] y con gentil brío y compostura se puso en la mitad del camino por donde forzosamente habían de pasar los encamisados [...] (QUI-ESP).

(24) [...] e con bella risolutezza e atteggiamento si piantò nel mezzo della strada, per dove gli incamiciati dovevano per forza passare [...] (QUI-IT).

(25) [...] et, plein de résolution et de vaillance, il vint se planter au beau milieu de la route, où ce cortège de chemises blanches ne tarderait pas à passer. (QUI-FR).

Para el valor de dirección, el español cuenta con el adverbio relativo de lugar adonde, que ha culminado un proceso de univerbación y que alterna en el uso con la forma analítica que aún puede presentar, a donde:

(26) [...] quedaba que los criados de don Luis se contentasen con volver tres y quedar uno para acompañarlo adonde don Fernando lo quería llevar [...] (QUI-ESP).

Sin embargo, el francés y el italiano ofrecen para la expresión del valor de la dirección un mayor número de casos de construcciones sin preposición. En estos contextos, la presencia de verbos de contenido direccional o de movimiento (Cano Aguilar 1981: 83) favorece la interpretación direccional, y hace innecesaria la aparición de una preposición antepuesta al adverbio relativo de lugar:

(27) [...] il ne restait plus qu'à convaincre trois des valets de don Luis de s'en retourner, tandis que le quatrième demeurerait pour accompagner son maître là où il plairait à don Ferdinand de le conduire. (QUI-FR).

(28) [...] restava che i servi di don Luigi acconsentissero che tre di loro se ne tornassero e uno rimanesse per accompagnare il padrone dove don Fernando desiderava condurlo. (QUI-IT).

En español, la extensión que cobran en el uso los grupos precedidos de preposición para la expresión de los distintos sentidos locativos favorece la formación, por analogía, de un grupo que refuerza el sentido de ubicación, en donde (vid. supra, ejemplo (2)). En nuestro corpus, sin embargo, no registramos ningún ejemplo de este grupo, debido probablemente a la aceptación desde el registro literario de las recomendaciones normativas que aconsejan evitar su uso (NGLE 2009: 22.8o). 
Por lo que se refiere a la expresión del sentido no locativo, observamos una situación peculiar en la comparativa de las tres lenguas, puesto que únicamente en español se observa un mayor número de casos precedidos de preposición (29), mientras que en francés apenas se recogen dos ejemplos (30) y en italiano no se registra ningún ejemplo con preposición antepuesta:

(29) Y esto es tan así, que me acuerdo yo que me decía mi abuela, por parte de padre [...] "Aquella, nieto, se parece a la dueña Quintañona"; de donde deduzco yo que la debió de conocer ella [...] (QUI-ESP, con valor continuativo).

(30) C'est tellement vrai que ma propre grandmère paternelle me disait [...] «Tu vois, mon enfant, cette damelà ressemble à la duégne Quintagnone.» D'où qu'elle devait la connaître [...] (QUI-FR, con valor continuativo).

Este análisis revela la autonomía de que goza en la actualidad el adverbio relativo où en la lengua francesa para integrarse en construcciones que favorecen lecturas locativas y no locativas en ausencia de preposición. La razón tal vez se halle en una mayor presencia del antecedente sintáctico en francés respecto del español y el italiano:

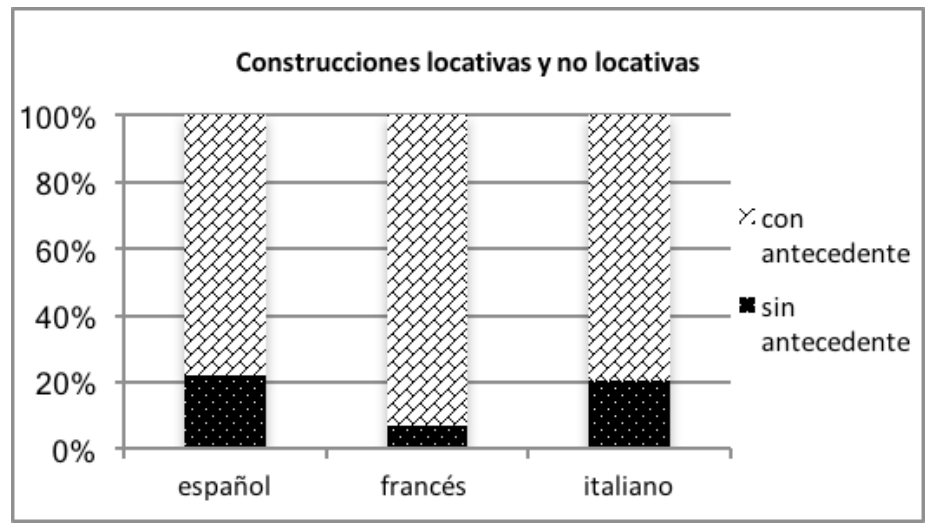

Gráfico 1: Presencia/ausencia de antecedente en español, francés e italiano

En francés, la aparición de antecedente sintáctico en el contexto oracional permite recuperar fácilmente el sentido de la construcción, de manera que resulta innecesaria la preposición para precisar el valor locativo con el que el adverbio relativo aparece $^{16 .}$

(31) $[\ldots]$ mais considère l'état où m'a réduit ton absence $[\ldots]($ QUI-FR, con sentido de ubicación).

(32) Ce faisant, j'accélere l'avènement fatal / où m'ont conduit tes fers, où s'achève mon mal. (QUI-FR, con sentido direccional).

(33) Sancho rechérit, le chevrier répliqua, et ainsi de suite, jusqu'au moment où les deux hommes se prirent par la barbe [...] (QUI-FR, con sentido no locativo).

16 El adverbio où se documenta desde el francés antiguo sin antecedente léxico. A partir del siglo XVI, en este entorno se prefiere la aparición del grupo là où (Rey 1992: s. v. où), siendo obligatoria la presencia de esta forma en caso de que encabece un periodo oracional (Sandfeld 1965: 117-118; Hanse 1983: 655) y llegando incluso a desplazar en algunos casos al adverbio où (Sandfeld 1965: 117):

a. J'irai (là) où vous irez (ap. Hanse 1983: 655): 'Iré (allí) donde usted vaya'.

b. Là où Jean réfléchit, Marianne agit (con valor temporal, ap. Hadermann 1993: 18): 'Cuando Jean piensa, Marianne actúa'. 


\subsection{Expresiones alternativas o equifuncionales}

Otro de los objetivos de nuestro trabajo es analizar el alcance de los cruces que en el uso pueden tener algunos de los adverbios relativos presentados anteriormente. Es el caso de los adverbios a dondeladonde y donde para la expresión de la dirección y la ubicación, en español; d'où y dont para el valor de procedencia, en francés; dove y ove para los sentidos de ubicación y dirección, y donde y onde para el sentido de procedencia, en italiano. Para ello, analizaremos los contextos de aparición de los adverbios relativos de lugar atendiendo al tipo de verbos con que aparecen (adonde a donde y donde), a la presencia de antecedente sintáctico en la oración (adonde - a donde y donde; d'où y dont), a la inserción de los adverbios en estructuras especificativas o explicativas (d'où y dont) y al sentido de las construcciones que introducen (dove - ove; donde - onde).

\subsubsection{Cruces existentes en español entre donde y a donde/adonde}

En español, existen dos formas para la expresión de la dirección mediante la anteposición de la preposición $a$ al adverbio relativo: la forma analítica, a donde, y la forma sintética, adonde. Tras un periodo de diferenciación en el uso de ambas formas a partir del criterio de la presencia o ausencia de antecedente sintáctico en la oración (Be1lo [1847] 2002: § 396), actualmente se consideran formas equivalentes (DPD 2005: s. v. adonde). No obstante, los cruces entre estas formas específicas para la expresión de la direccionalidad y el adverbio donde se han sucedido a lo largo de la historia y aún en la actualidad se acepta normativamente incluso el uso de este último adverbio sin preposición (Diccionario de la lengua española ${ }^{17}$ 2014: s. v. donde; NGLE 2009: $\S 22.8$ p) (34) mientras que, por otro lado, se censura el uso de a donde/adonde para la expresión de la ubicación (Seco 2011: s. v. adonde; NGLE 2009: § 22.8r) (35). Sin embargo, encontramos ejemplos de uno y otro uso:

(34) He llegado donde no pensaba llegar (Pombo Ventana, ap. NGLE 2009: § 22.8p).

(35) Y adonde está el faro había una torre de piedras unas encima de otras (Quiñones Hortensia, ap. NGLE 2009: § 22.8r).

La consulta en nuestro corpus de adverbios relativos de lugar con valor de dirección en español arroja los siguientes resultados:

\begin{tabular}{|c|c|c|c|c|c|c|}
\hline \multirow{4}{*}{$\begin{array}{c}\text { sentido } \\
\text { direccional }\end{array}$} & \multicolumn{2}{|c|}{ donde } & \multicolumn{2}{c|}{ adonde } & \multicolumn{2}{c|}{ a donde } \\
\cline { 2 - 7 } & $\begin{array}{c}\text { con } \\
\text { antecedente }\end{array}$ & $\begin{array}{c}\text { sin } \\
\text { antecedente }\end{array}$ & $\begin{array}{c}\text { con } \\
\text { antecedente }\end{array}$ & $\begin{array}{c}\text { sin } \\
\text { antecedente }\end{array}$ & $\begin{array}{c}\text { con } \\
\text { antecedente }\end{array}$ & $\begin{array}{c}\text { sin } \\
\text { antecedente }\end{array}$ \\
\cline { 2 - 7 } & 6 & 11 & 2 & 39 & 0 & 1 \\
\hline
\end{tabular}

Tabla 2: Adverbios y grupos adverbiales con sentido direccional en español

De este modo vemos que, a diferencia de lo que ocurre con el francés y el italiano, lenguas en las que los adverbios relativos où y dove expresan en la mayor parte de los ejemplos registrados el sentido direccional sin usar preposición (vid. supra, Tabla 1), el corpus del español recoge una mayoría de casos con preposición para

\footnotetext{
En adelante, $D L E$.
} 
la expresión del sentido direccional (71\%) -adonde (41 casos) / a donde (1 caso)-, frente a una minoría de ejemplos en que el adverbio relativo donde aparece solo $(29 \%, 17$ casos). En estos últimos casos, la presencia de verbos de movimiento y dirección ${ }^{18}$ favorece también en español la lectura direccional de la construcción sin preposición, al igual que ocurría con la expresión de la direccionalidad en francés e italiano. La aparición del antecedente -que se registra en más de una tercera parte de las muestras (35\%)- también contribuye al sentido direccional del conjunto:

(36) Te ruego [...] que no me deje perecer en esta prisión donde ahora me llevan, hasta ver cumplidas tan alegres e incomparables promesas [...] (QUI-ESP).

(37) [...] y sintió tanto el haberla perdido, que murió de pesar en el camino de Constantinopla, donde lo llevaron cautivo. (QUI-ESP).

Por el contrario, en los ejemplos en que se documenta a donde/adonde predominan los contextos oracionales sin antecedente explícito (95\%: 40 de los 42 casos registrados), puesto que la presencia de la preposición ayuda a identificar el sentido a la construcción:

(38) Su padre llegó corriendo adonde estábamos [...] (QUI-ESP).

(39) [...] no le importó nada venir adonde estaba su padre conmigo [...] (QUI-ESP).

Si bien el grupo a donde/adonde se identifica con claridad como la fórmula preferente para la expresión de la dirección, sorprende el hecho de que se documente en nuestro corpus con valor de ubicación, ya que el español entiende el adverbio sin preposición como la forma no marcada para la expresión de la ubicación, mientras que los grupos formados por prep. + adverbio relativo son los encargados de transmitir los restantes sentidos locativos:

(40) [...] y mañana le vienen a enterrar con gran pompa adonde tengo dicho. (QUIESP) ${ }^{19}$.

(41) ¡Ay de aquel que navega, el cielo oscuro, / por mar no navegado e incierta vía, / adonde norte o puerto no se ofrece. (QUI-ESP).

Con estos ejemplos confirmamos la incursión de a dondeladonde en los entornos sintácticos propios de donde, tal como recogían las obras normativas que citábamos más arriba (DLE 2014: s. v. donde; NGLE 2009: § 22.8p). Para evaluar el alcance de este cruce entre adverbios y sentidos locativos, sería necesario un estudio más amplio que considerara la diacronía del fenómeno.

\subsubsection{Posible alternancia entre las formas d'où y dont}

Respecto al francés, vamos a analizar la posible alternancia en el uso que presentan el grupo d'où y el pronombre $d o n t^{20}$. Este último pronombre contiene etimológicamente la preposición de en su forma y aplica este valor preposicional en muchos de sus usos, por lo que los límites entre dont y d'où $(<d e+o u ̀)$ son controvertidos. La gramática normativa considera la posibilidad de distinguir las dos formas a partir de

18 En este trabajo distinguiremos entre verbos de movimiento - cuando aluden a un desplazamiento físico sin mayor especificación (i. e. andar, pasear, correr)-y direccionales -cuando ese desplazamiento físico se orienta en una dirección determinada: arriba/abajo, dentro/fuera, etc.- (Cano Aguilar 1981: 83).

19 La presencia de un verbo de contenido direccional en la cláusula principal (vienen) puede hacer pensar en una lectura direccional del adverbio relativo de lugar; sin embargo, este último depende del verbo de contenido estático enterrar, por lo que prevalece la interpretación locativa de ubicación: 'enterrar EN un lugar'.

20 Como comentábamos anteriormente (vid. supra, §3.1), junto a où, encontramos el pronombre relativo dont, término que antiguamente pudo expresar origen o procedencia en relación a un antecedente no locativo (animado), 
la referencia a un movimiento real de un cuerpo en el espacio, d'où (42), o la alusión a la descendencia, dont (43) (Hadermann 1993: 160); sin embargo, en el uso real se intercambian fácilmente cuando el contexto lingüístico puede presentar algún tipo de ambigüedad, como puede ser la referencia a un movimiento figurado (Dubois 1965: 176); así lo vemos en (44):

(42) la ville d'où il vient est à plus de 3000 kilomètres d'ici (ap. Hadermann 1993: 160): 'la ciudad de donde viene está a más de 3000 kilómetros de aquí'.

(43) la ville dont il vient est le type même des insipides bougades de province (ap. Hadermann 1993: 160): 'la ciudad de la que procede es del mismo tipo que las insípidas aldeas de provincia'.

(44) La baie du restaurant d'où l'on découvre toute la vallée... (ap. Dubois 1965: 176): 'El rincón del restaurante desde donde se descubre todo el valle'.

Además, existen contextos lingüísticos difíciles de clasificar a partir del reconocimiento del concepto de desplazamiento físico o procedencia abstracta; por tanto, las formas $d$ 'où y dont resultan fácilmente intercambiables (Hadermann 1993: 158):

(45) Il regarde fixement la joue sur laquelle glissent lentement les larmes. Un regard d'où l'homme semble absent (Vailland, Drôle de jeu, p. 123, ap. Hadermann 1993: 158): 'Él mira fijamente la mejilla sobre la que se deslizan lentamente las lágrimas. Una mirada de donde el hombre está ausente'.

En nuestro corpus registramos el grupo d'où en 26 ocasiones, de las cuales identificamos trece entornos oracionales en los que sería posible la aparición del pronombre dont. Los factores que permitirán la aparición del pronombre dont en lugar de d'où son, en primer lugar, la presencia de un antecedente de contenido locativo que aluda preferentemente a la procedencia abstracta (46) y (47) o bien a la procedencia física (48) y (49) y, en segundo lugar, la inserción del adverbio relativo en una estructura relativa especificativa (46)-(49) y no explicativa:

\begin{tabular}{|c|c|c|c|c|}
\hline \multirow{3}{*}{ d'où = dont } & \multicolumn{2}{|c|}{ antecedente abstracto } & \multicolumn{2}{c|}{ antecedente concreto } \\
\cline { 2 - 5 } & $\begin{array}{c}\text { relativa } \\
\text { especificativa }\end{array}$ & $\begin{array}{c}\text { relativa } \\
\text { explicativa }\end{array}$ & $\begin{array}{c}\text { relativa } \\
\text { especificativa }\end{array}$ & $\begin{array}{c}\text { relativa } \\
\text { explicativa }\end{array}$ \\
\cline { 2 - 5 } & 3 & 2 & 8 & 0 \\
\hline
\end{tabular}

Tabla 3: Condicionantes gramaticales en los contextos en que d'où y dont son equivalentes

(46) La fausseté de tes promesses et la certitude de mon malheur me mènent en un

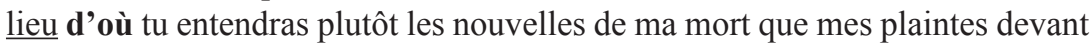
tes rigueurs. (QUI-FR).

(47) Et le plus admirable, c'est qu'un soldat n'est pas plus tôt tombé à l'endroit d'où il ne se relèvera plus jusqu'à la fin des temps, qu'un autre déjà occupe sa place $[\ldots]$ (QUI-FR).

si bien en la actualidad este valor se reserva a de qui-empleado con antecedente animado, a diferencia de où, d'où, adverbio relativo de lugar empleado con antecedentes inanimados-(Hanse 1983: 338):

a. L'homme dont j'ai ici une lettre (ap. Hanse 1983: 338. En este ejemplo el pronombre relativo equivale a cuyo y complementa a lettre 'carta'): 'El hombre cuya carta tengo aquí'.

b. $\quad$ L'homme de qui j'ai reçu une lettre (ap. Hanse 1983: 338. En este ejemplo, el grupo de qui expresa valor de procedencia a partir de un antecedente no locativo, homme 'el hombre'; complementa pues al verbo j'ai reçu 'he recibido'): 'El hombre del que he recibido una carta'. 
(48) [...] au contraire, dissimulant du mieux qu'il put son émotion, il avança du côte d'où lui semblaient venir le bruit de l'eau et des coups. (QUI-FR).

(49) $[\ldots]$ tu trouverais que j'ai montré beaucoup de patience en n'écrasant pas les lèvres d'où sortait pareil blasphème. (QUI-FR).

Tras la recopilación de los datos observamos que los contextos lingüísticos en los que el grupo d'où puede sustituirse por el pronombre dont presentan, en la mayoría de los casos, un antecedente concreto (8 casos) que precede en todos los ejemplos estudiados a una estructura relativa especificativa, mientras que en los casos en que el antecedente es abstracto (5 casos) se documentan ejemplos de estructuras especificativas (3 casos) y explicativas ( 2 casos). Dicho de otra manera, cuanto mayor es el nivel de abstracción del referente locativo al que alude el antecedente, más posibilidades existen de intercambiar el grupo $d$ 'ou y el pronombre dont, ya que en estos contextos la inserción de estos términos en relativas especificativas o explicativas no determina la alternancia de ambos:

(50) Consolé, Sancho déclara qu'en ce cas il n'avait plus de souci à se faire, parce que la lettre à Dulcinée, il avait presque entière dans sa mémoire, d'où il pourrait la ressortir où et quand on voudrait. (QUI-FR).

Sin embargo, en los casos en que el antecedente alude a un lugar concreto o físico, el tipo de relativa en que se inserta el grupo d'où parece condicionar su sustitución por dont, puesto que dicha equivalencia solo se produce en estructuras relativas especificativas. De esta manera, observamos que la mayor parte de las construcciones documentadas en nuestro corpus en que d'où podría intercambiarse por el pronombre dont se hallan en estructuras relativas especificativas (11 casos) mientras que, allí donde se registran estructuras explicativas (2 casos), el antecedente ha de ser obligatoriamente de naturaleza abstracta para que ambos términos puedan alternarse (50)-(51):

(51) Aussi, quand le paysan lui redemanda, comment il se sentait, il lui répondit, mot pour mot, ce que l'Abencérage avait dit à Rodrigue de Narvaez, dans la «Diane» de Montemayor, d'où cette histoire est tirée [...] (QUI-FR $)^{21}$.

Estos entornos oracionales que favorecen la alternancia de d'où y dont evidencian las conexiones entre el adverbio relativo de lugar y el pronombre relativo en francés en una esfera de significado, la procedencia abstracta, que ha permitido el acercamiento entre términos bien delimitados gramaticalmente.

\subsubsection{Uso y alternancia entre las formas dove - ove y donde - onde}

Por último, en la lengua italiana, junto a dove conviven tres formas propias del re-

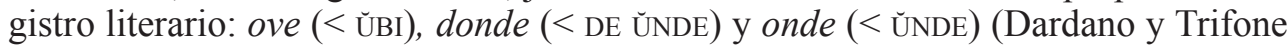
1985: 179; Tekavčić 1980: 411), asociadas a los sentidos de ubicación (ove) (52) y procedencia (donde, onde) (53) y (54):

(52) una piccola cena per ir morti che ritornano nella casa ove vissero (Deledda, ap. Serianni 1989: 323): 'una pequeña cena para los muertos que vuelven a la casa donde vivieron'.

(53) le torri dei radi paeselli donde si parte un suono di campane (Nievo, ap. Serianni 1989: 323): 'las torres de los aislados pueblecillos de donde parte un sonido de campanas'.

1 La metonimia con que se presenta el antecedente de d'où (en la Diana de Montemayor = en el libro llamado la Diana de Montemayor) eleva el nivel de abstracción con que aquel se presenta en la oración. 
(54) Il libro onde mi servo per insegnare la storia è questo: 'el libro del cual [de donde] me sirvo para enseñar la historia es éste’ (ap. Llovera 1956: 260).

Como veíamos más arriba, se diferencian dos adverbios destinados a la expresión de los sentidos de ubicación y dirección, dove y ove (ant.), y otros dos encargados de transmitir el valor de la procedencia, donde y onde (ant.) ${ }^{22}$. En nuestro corpus, en cambio, hallamos una presencia desigual de estos términos. Como vemos en la Tabla 4, el adverbio dove se documenta con mucha más frecuencia que los restantes adverbios, donde y onde, y ove no se registra:

\begin{tabular}{|c|c|c|}
\hline & $\#$ & Frec. rel. \\
\hline dove & 319 & 97 \\
\hline ove & 0 & 0 \\
\hline onde & 2 & 0,6 \\
\hline donde & 8 & 2,4 \\
\hline
\end{tabular}

Tabla 4: Registro de adverbios relativos de lugar en QUI-IT

El adverbio relativo principal del italiano, dove, se documenta con todos los sentidos locativos estudiados -ubicación, procedencia, trayecto y dirección- y con algunos sentidos no locativos que se presentarán más adelante (vid. infra, § 3.3). La anteposición de una preposición facilita la lectura locativa con sentido de procedencia (55) y trayecto (56), como vimos anteriormente (vid. supra, Tabla 1), aunque también es posible que el adverbio refleje estos valores sin estar precedido de preposición (57) y (58):

(55) $[\ldots]$ volgendo anche lui il viso là di dove si sentiva venire il suono [...] (QUIIT).

(56) Gl'indicammo la finestrina di dove appariva la canna [...] (QUI-IT).

(57) -Non mi alzero più di qui dove sono, o valente cavaliere, insino a che la vostra cortesia non mi largisca un dono che intendo chiederle [...] (QUI-IT).

(58) Essi allora ammainarono le vele e gettarono in mare lo schifo o imbarcazione, dove entrarono circa dodici franesi ben armati [...] (QUI-IT).

Por su parte, el adverbio donde, restringido al ámbito literario y asociado al sentido de procedencia, expresa este valor locativo en todas sus apariciones en la obra:

(59) $[. .$.$] insino a tanto che io chieda alla principessa Micomicona licenza di poterlo$ soccorrere nella sua tribolazione, donde abbiate per certo che io lo trarrò s'ella mel conceda. (QUI-IT).

(60) $[. .$.$] però non mi giovò a nulla questo mio onesto desiderio rispetto all'impedirmi$ di andare là donde non spero tornar più [...] (QUI-IT).

Hasta aquí observamos que los dos adverbios clasificados como formas modernas en algunas gramáticas (Tekavčić 1980: 411) presentan en nuestro corpus un uso que se corresponde con el descrito en las gramáticas consultadas: dove expresa distintos sentidos locativos, en ocasiones, precedido de preposición; donde queda restringido al ámbito literario y expresa el valor de procedencia.

Sin embargo, el análisis de los adverbios onde y ove ofrece unos resultados diferentes a los recogidos en las obras de referencia. En cuanto a onde, forma propia del

22 En algunas gramáticas, además, se precisa que los adverbios ove y onde no solo están restringidos al ámbito literario, sino que también son formas anticuadas (Tekavčić 1980: 411). 
ámbito literario con valor de procedencia, expresa sentido de ubicación en los dos ejemplos de su uso que hemos hallado en nuestro corpus:

(61) "O cavaliere, chiunque tu sia, che questo pauroso lago stai a riguardare, se brami conseguire il bene che sotto di queste negre onde si cela, mostra il valore del tuo saldo cuore [...] (QUI-IT).

(62) I pudori inopportuni, / Onestà contro l'usato, / Son le nubi onde si cela / Quando più cerco vederla. (QUI-IT).

Este hecho puede conducirnos a afirmar que hoy el adverbio relativo onde es un adverbio cuyo uso está condicionado diafásica y diacrónicamente, y que puede documentarse con el valor locativo menos marcado, la ubicación, tras haberse desdibujado su sentido original de procedencia.

La ausencia de ejemplos de ove nos impide analizar su uso. Sin embargo, este hecho sugiere una próxima desaparición del término en el ámbito literario, situación que podría analizarse en profundidad ampliando el corpus de estudio sincrónico.

Estas aproximaciones al estado en que se encuentran los adverbios relativos de lugar en italiano deben ser completadas con un análisis sincrónico más amplio que considere distintos géneros literarios y autores.

\subsection{Extensión hacia valores no locativos}

Por otro lado, en todas las lenguas analizadas se ha producido un desplazamiento semántico en las construcciones con adverbios relativos de lugar hacia otras nociones como la temporalidad, la finalidad o la causa. En español actual identificamos sentidos no locativos en la lengua popular de algunos países de Latinoamérica como Chile, Venezuela, Panamá, Costa Rica, Guatemala, entre otros (NGLE 2009: $\S 22.8 \mathrm{u}$ ): el sentido causal (Kany 1976: 452) (63), el valor temporal (NGLE 2009: § 22.8u) (64), la expresión de la consecuencia (NGLE 2009: § 22.8u) (65), e incluso la condicionalidad (Kany 1976: 452) (66):

(63) Pedro ha perdido la salud, donde trasnochaba tanto (Román, ap. Kany 1976: 452).

(64) Donde te vi, me asusté (ap. NGLE 2009: § 22.8u).

(65) Me gasté la plata que tenía, donde no me queda nada (ap. NGLE 2009: § $22.8 \mathrm{u})$.

(66) Es mi hijo. Donde le toques un pelo, te rajo (Diez-Canseco Baldomera, ap. Kany 1976: 453).

En la actualidad, el adverbio relativo où puede expresar valores no locativos (Hadermann 1993: 66), entre los que destaca el sentido temporal (Sandfeld 1965: 118) (67) y (68), condicional (Hadermann 1993: 66) (69) e incluso adversativo (Sandfeld 1965: 119) (70), algunos de los cuales están restringidos al ámbito literario ${ }^{23}$ :

(67) Pendant le temps où elle vaquait aux soins du ménage (Balzac, ap. ReyDevobe y Rey 1993: s. v. où): 'Durante el tiempo en que ella se ocupaba de las tareas del hogar'.

(68) Au moment où il arriva (ap. Rey-Devobe y Rey 1993: s. v. où): 'Al momento en que él llegó'.

(69) Où son coeur contredisait ses principes, ses principes étaient d'avance vaincus 
(M. Salomon Ch. Nodier 6, ap. Sandfeld 1965: 118-119): 'Si su corazón contradecía sus principios, sus principios estaban derrotados de antemano'.

(70) Je ne suis qu'un caricaturiste! Et c'est pitié, là où il faudrait un critique (Benj. Farce, ap. Sandfeld 1965: 118): ‘¡Solo soy un dibujante! Y es una lástima, pero necesitaría un crítico'.

En italiano, dove y ove pueden evolucionar desde un valor espacial a la referencia temporal, un uso que en la actualidad se considera obsoleto (De Mauro 2000: s. v. dove; Grande Dizionario Hoepli Italiano di Aldo Gabrielli 2011: s. v. dove) (71); también al sentido condicional (Tekavčić 1980: 412; Treccani 1986, s. v. dove y ove) (72) e incluso a un valor adversativo (Treccani 1986, s. v. dove; De Mauro 2000: s. v. dove) (73):

(71) una donnaccia, la zingara, toccò con la punta dell'indice il lembo della giacca all'ingegnere, che credette ad un borseggio, dove si trattava di venerazione (Faldella, ap. Serianni 1989: 610): 'Una mujerzuela, la gitana, tocó con la yema del dedo índice el borde de la cazadora del ingeniero, que pensó que le estaban robando, cuando en realidad le estaba adulando'.

(72) dove io tardassi, provvedi tu a tutto (ap. Treccani 1986, s. v. dove): 'en caso de que yo tardase, encárgate tú de todo'.

(73) a me fu utile, dove a te fu causa di rovina (ap. De Mauro 2000: s. v. ove): 'fue útil para mí, aunque fue la causa de tu ruina'.

Por su parte, donde y onde tienen la capacidad de transmitir, especialmente después de pausa, valor causal (74) o consecutivo (75) (Serianni 1989: 323; Tekavčić 1980: 412; Treccani 1986, s. v. onde). Se documenta también el valor final asociado a la forma onde (76) (Tekavčić 1980: 412; Treccani 1986, s. v. onde):

(74) a Roma [...] le 'canterine' venivano proibite. Donde lunghe contese, e infrazioni al divieto medesimo (F. Cardini, ap. Serianni 1989: 323): ‘en Roma las "cantarinas" estaban prohibidas. A causa de ello, hay largas disputas e infracciones en torno a la misma prohibición'.

(75) onde avvenne che...; onde segue, onde si deduce che... (ap. Treccani 1986, s. v. onde): 'Por lo que sucedió que...; de lo que sigue, de lo que se deduce que...'.

(76) ho voluto insistere onde si convincessero (ap. Treccani 1986, s. v. onde): 'He querido insistir para que se convenciera'.

La mayor parte de estos sentidos no locativos son propios del ámbito literario (Grande Dizionario Hoepli Italiano di Aldo Gabrielli 2011 s. v. dove, ove, donde, onde; Dizionari Garzanti Linguistica 2017: s. v. dove, ove, donde, onde).

El estudio en nuestro corpus de los adverbios relativos de lugar con sentido no locativo ofrece los siguientes resultados. El español registra hasta cuatro valores no locativos en la obra estudiada: continuativo (84), anafórico relativo causal (85), temporal (77) y anafórico relativo instrumental (88). Por su parte, el francés muestra también cuatro sentidos locativos, si bien el mayor número de ejemplos con sentido no locativo se vinculan a una lectura temporal (87), siendo minoritarios los sentidos anafórico relativo (86), anafórico relativo causal (79) y continuativo (30). Por último, el italiano recoge un escaso número de ejemplos con sentido no locativo entre los que se documentan los valores temporal (78) y anafórico relativo causal (80): 


\begin{tabular}{|c|c|c|c|c|c|c|}
\hline \multirow{2}{*}{} & \multicolumn{2}{|c|}{$\begin{array}{c}\text { donde } \\
\text { (esp.) }\end{array}$} & \multicolumn{2}{c|}{ où (fr.) } & \multicolumn{2}{c|}{ dove (it.) } \\
\cline { 2 - 7 } & $\#$ & $\begin{array}{c}\text { fre. } \\
\text { rel. }\end{array}$ & $\#$ & $\begin{array}{c}\text { fre. } \\
\text { rel. }\end{array}$ & $\#$ & $\begin{array}{c}\text { fre. } \\
\text { rel. }\end{array}$ \\
\hline continuativo & 13 & 65 & 1 & 1,4 & 0 & 0 \\
\hline temporal & 3 & 15 & 63 & 87,5 & 3 & 75 \\
\hline anafórico relativo causal & 3 & 15 & 3 & 4,2 & 1 & 25 \\
\hline anafórico relativo & 1 & 5 & 0 & 0 & 0 & 0 \\
\hline instrumental & 0 & 0 & 5 & 6,9 & 0 & 0 \\
\hline
\end{tabular}

Tabla 5: Frecuencias valores no locativos de donde, où y dove

Como decíamos anteriormente (vid. supra, § 3.1), el español es la única de las tres lenguas que utiliza mayoritariamente el adverbio precedido de preposición para la expresión de valores no locativos (29). Sin embargo, en lo referente al antecedente sintáctico de estas construcciones, las tres lenguas tienen un comportamiento similar, ya que la presencia explícita del antecedente en la oración es la situación más habitual para los usos con sentido no locativo estudiados, a excepción del sentido temporal, principalmente en español e italiano (80)- $(82)^{24}$ :

(77) [...] y aquí fue la última vez donde Marcela lo acabó de desengañar y desdeñar [...] (QUI-ESP, con sentido temporal).

(78) [...] qui fu l'ultima volta dove Marcella finì di disingannarlo e respingerlo per modo che egli pose termine alla tragedia della sua miseranda vita [...] (QUI-IT, con sentido temporal).

(79) Oui, mais je m'arrangerai pour que plus personne ne se le permette, ou je m'arracherai avec les dents tous les poils que j'ai où je pense. (QUI-FR, con sentido anafórico relativo causal).

(80) - Mi chiamano così — rispose Ginesio; - ma io farò in modo che non mi si dia più questo nome, o me la rifaccio con la barba che ho dove m'intendo io. (QUI-IT, con sentido anafórico relativo causal).

(81) [...] que no hay refrán que no sea verdadero, porque todos son sentencias sacadas de la misma experiencia, madre de todas las ciencias, especialmente aquel que dice: donde una puerta se cierra, otra se abre. (QUI-ESP).

(82) Les proverbes disent vrai, car ce sont des maximes tirées de l'expérience, mère de toutes les sciences; et celui-ci me parait venir fort à propos: où une porte se ferme, une autre s'ouvre. (QUI-FR).

24 En español e italiano el $67 \%$ de las construcciones con sentido temporal no tiene antecedente sintáctico, mientras que en francés el $98.4 \%$ de los ejemplos con valor temporal cuenta con un antecedente explícito en la oración. 
(83) [...] non ci sia proverbio che non dica il vero, giacché son tutte sentenze ricavate appunto dalla esperienza, madre d'ogni scienza; specialmente quello che dice: "Dove si chiude una porta, un'altra se n'apre". (QUI-IT).

Al igual que ocurría con los valores locativos (vid. supra), en la expresión de los sentidos no locativos podemos encontrar fórmulas gramaticales alternativas (84)-(87) o distintas interpretaciones no locativas a partir de cada traducción (88) y (89):

(84) [...] y al cabo se vino a llamar don Quijote; de donde los autores de esta tan verdadera historia dedujeron, como queda dicho, que si duda se debía de llamar Quijada [...] (QUI-ESP, con sentido continuativo) ${ }^{25}$.

(85) Por esto querría que la fortuna me ofreciese pronto alguna ocasión donde me hiciese emperador, para mostrar mi pecho haciendo el bien a mis amigos [...] (QUI-ESP, con sentido anafórico relativo causal) ${ }^{26}$.

(86) Si cette douleur que j'ai au côté me laissait quelque répit, je te ferais comprendre, Sancho, l'erreur où tu te trouves. (QUI-FR, con sentido anafórico relativo) ${ }^{27}$.

(87) [...] vu les victoires que vous avez dû remporter à l'époque où je n'étais pas encore à votre service. (QUI-FR, con sentido temporal) ${ }^{28}$.

(88) [...] le pone al hombre bajo los pies cualquier cosa donde tropiece y caiga [...] (QUI-ESP, con sentido anafórico relativo instrumental).

(89) $[\ldots]$ et puis le jour où on tombe, on ne comprend pas pourquoi. (QUI-FR, con sentido anafórico relativo causal).

\section{Conclusiones}

En la Tabla 6 recogemos los adverbios relativos de lugar en español, francés e italiano; los valores locativos que pueden expresar; los cruces que existen entre algunas de sus formas y los sentidos no locativos que expresan en determinados contextos.

25 Las traducciones de este pasaje en francés e italiano no emplean adverbios relativos de lugar:

a. [...] décida de s'appeler don Quichotte (les auteurs de cette véridique histoire en ont conclu qu'il devait se nommer Quichada, et non Quesada, comme certains l'ont prétendu). (QUI-FR).

b. [...] finché riuscì a chiamarsi don Chisciotte: dal che, come s'è detto, arguirono gli scrittori di questa vera storia che, sicuramente si doveva chiamare Chisciada e non Chesada, come altri vollero dire. (QUI-IT).

26 Las traducciones de este pasaje en francés e italiano no emplean adverbios relativos de lugar:

a. Voilà pourquoi je voudrais que la fortune m'offrît au plus vite l'occasion de devenir empereur: pour prouver mon bon cœur en faisant le bien à mes amis [...] (QUI-FR).

b. $\quad{ }^{\text {Per }}$ questo vorrei che la fortuna mi presentasse presto un'occasione per cui divenire imperatore, affine di mostrare il cuore che ho facendo del bene ai miei amici [...] (QUI-IT).

27 Las traducciones de este pasaje en español e italiano no emplean adverbios relativos de lugar, sino construcciones de preposición + pronombre relativo:

a. Quisiera tener aliento para poder hablar un poco descansado, y que el dolor que tengo en esta costilla se aplacara un poco, para darte a entender, Panza, el error en que estás. (QUI-ESP).

b. Vorrei avere fiato da poter parlare un po' riposatamente, e che il dolore che sento a questa costola si mitigasse tanto quanto per farti capire, o Panza, l'errore in cui sei. (QUI-IT).

28 Las traducciones de este pasaje en español e italiano no emplean adverbios relativos de lugar:

a. [...] conforme a las muchas victorias que vuestra merced ha ganado y ganó en el tiempo que yo aún no era su escudero. (QUI-ESP).

b. [...] poiché molte debbono essere le vittorie che vossignoria ha guadagnato e già guadagnò quando io non ero ancora suo scudiero. (QUI-IT). 


\begin{tabular}{|c|c|c|c|c|}
\hline & & Español & Francés & Italiano \\
\hline \multicolumn{2}{|c|}{$\begin{array}{l}\text { Adverbios relativos de lu- } \\
\text { gar y étimos latinos }\end{array}$} & $\begin{array}{l}\text { donde }<(\mathrm{DE}) \text { ŬNDE } \\
\text { adonde }<\mathrm{a}+\text { donde }\end{array}$ & 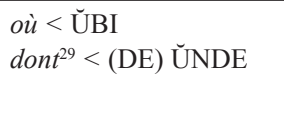 & $\begin{array}{l}\text { dove, ove }<\text { ŬBI } \\
\text { onde, donde }<\text { (DE) } \\
\text { ŬNDE }\end{array}$ \\
\hline \multirow{4}{*}{$\begin{array}{l}\text { Valores loca- } \\
\text { tivos }\end{array}$} & ubicación & (en) donde & où & dove, ove (lit.) \\
\hline & $\begin{array}{l}\text { proce - } \\
\text { dencia }\end{array}$ & de donde & d'où & $\begin{array}{l}\text { di dove, da dove, donde } \\
\text { (lit.), onde (lit.) }\end{array}$ \\
\hline & dirección & $\begin{array}{l}\text { a donde - adonde } \\
\text { donde }\end{array}$ & $\begin{array}{l}\text { jusqu'où } \\
\text { où }\end{array}$ & dove, ove (lit.) \\
\hline & trayecto & por donde & par où & per dove \\
\hline \multicolumn{2}{|c|}{$\begin{array}{l}\text { Cruces entre formas ad- } \\
\text { verbiales relativas en la } \\
\text { actualidad }\end{array}$} & $\begin{array}{l}\text { donde / a donde - adonde } \\
\text { donde / en donde }\end{array}$ & d'où / dont & $\begin{array}{l}\text { En el uso literario: } \\
\text { Procedencia: onde } \\
\text { (ant.), donde (act.) } \\
\text { Ubicación: ove (ant.), } \\
\text { dove (act.) }\end{array}$ \\
\hline \multicolumn{2}{|c|}{$\begin{array}{l}\text { Valores no locativos ex- } \\
\text { presados por los adverbios } \\
\text { relativos de lugar }\end{array}$} & $\begin{array}{ll}\text { - } & \text { temporal (Amér., pop.) } \\
\text { - } & \text { continuativo (Amér., } \\
& \text { pop.) } \\
\text { - } & \text { anafórico-relativo causal } \\
\text { - } & \text { anafórico-relativo instru- } \\
& \text { mental } \\
\text { - } & \text { causal (Amér., pop.) } \\
\text { - } & \text { condicional (Amér.) }\end{array}$ & $\begin{array}{ll}\text { - } & \text { temporal } \\
\text { - } & \text { continuativo (lit.) } \\
\text { - } & \text { anafórico-relativo } \\
& \text { (lit.) } \\
\text { - } & \text { anafórico-relativo } \\
& \text { causal (lit.) } \\
\text { - } & \text { condicional (lit.) } \\
\text { - } & \text { adversativo (lit.) }\end{array}$ & $\begin{array}{ll}\text { - } & \text { temporal (ant.) } \\
\text { - } & \text { continuativo (lit.) } \\
\text { - } & \text { anafórico-relativo } \\
\text { anafórico-relativo } \\
\text { causal (lit.) } \\
\text { - } & \text { final } \\
\text { - } & \text { causal (lit.) } \\
\text { - condicional (poc. } & \text { us.) } \\
\text { - adversativo (ant., } & \text { lit.) }\end{array}$ \\
\hline
\end{tabular}

Tabla 6: Relación de adverbios relativos de lugar en español, francés e italiano.

Tras el análisis del comportamiento de los adverbios relativos de lugar en las distintas lenguas romances contempladas en este trabajo a partir del corpus de estudio, creemos que pueden extraerse varias conclusiones.

En primer lugar, los adverbios relativos que aparecen hoy en las lenguas estudiadas derivan de dos de las cuatro formas existentes en latín: ǓBI y ǓNDE. De ǓBI proceden los principales adverbios relativos de lugar en francés (où) e italiano (dove); mientras que ǓNDE es el adverbio del que procede el relativo actual en español (donde). Por su parte, el español es la única lengua romance que en la actualidad conserva tan solo una única forma heredera de las cuatro formas latinas existentes para expresar el lugar, donde, mientras que el francés y el italiano mantienen actualmente varios derivados del latín (francés: où, dont; italiano: dove, ove, onde, donde) -si bien algunas de esas formas han perdido su categoría de adverbio relativo: en francés, dont ha quedado como un pronombre relativo-.

Por otro lado, la expresión de los distintos valores locativos se ha desarrollado históricamente a partir de la anteposición de preposiciones al adverbio relativo de

29 Como se ha explicado anteriormente, en la actualidad esta forma ha perdido el valor de adverbio y funciona como pronombre relativo (vid. supra, § 3.1). 
lugar en cada una de las lenguas estudiadas. De esta forma, a excepción del registro literario en italiano -que diferencia entre formas que expresan ubicación y dirección (dove, ove), por un lado, y formas destinadas a expresar la procedencia (donde, onde), por otro-, las lenguas romances contempladas en este trabajo han abandonado el empleo de otras formas relativas para expresar diversos matices locativos, identificando el adverbio relativo principal con el valor de ubicación y anteponiendo distintas preposiciones para precisar los sentidos locativos de procedencia (de donde, en español; d'où, en francés; di dove, da dove, en italiano), dirección (a donde, en español; jusqu'où, en francés) y trayecto (por donde, en español; par où, en francés; per dove, en italiano). Sin embargo, observamos diferencias en las lenguas estudiadas puesto que, mientras en español esta situación se plantea en la mayor parte de los sentidos locativos, el italiano la contempla para los sentidos de procedencia y trayecto, y el francés únicamente la mantiene para el valor de origen de manera mayoritaria (vid. supra, Tabla 1). Este procedimiento utilizado en las distintas lenguas favorece la economía lingüística del sistema, toda vez que los adverbios relativos dejan de transmitir por sí mismos un valor locativo determinado, evitando la proliferación de términos diferentes para la expresión de distintos matices locativos y haciendo recaer dichos valores en el sistema formado a partir de las preposiciones que se anteponen a aquellos.

El procedimiento gramatical que acabamos de repasar, por el cual las lenguas estudiadas expresan los distintos matices locativos mediante la anteposición de una preposición, no se cumple plenamente en la expresión de la dirección en francés e italiano $^{30}$. Para este sentido locativo, hallamos adverbios que, sin estar precedidos de preposición, aluden a la dirección (en francés, où; italiano, dove; e incluso en español, donde, vid. supra, (36) y (37)), al tiempo que, en lenguas como el español, se documentan formas con preposición que expresan valor de ubicación (es el caso de adonde, vid. supra, (40) y (41)). De este modo, observamos que la direccionalidad y la ubicación son valores locativos que en la actualidad se acercan formalmente, siendo en estos casos determinante el contexto oracional y, en concreto, la semántica de los verbos empleados, a través de los cuales se puede determinar el valor locativo con el que los adverbios se utilizan en cada caso.

Este cruce de formas diferentes en determinados entornos sintácticos demuestra, por otra parte, la inestabilidad propia del sistema lingüístico en el campo de los adverbios relativos de lugar. Esto justifica la flexibilidad normativa que se aplica a estos adverbios en las diferentes lenguas, principalmente en lo referido en español al adverbio donde frente a los grupos a donde/adonde para la expresión de la ubicación y la dirección; en francés, con respecto a d'où y dont cuando expresan procedencia; y en italiano, con el mantenimiento de cuatro formas adverbiales relativas condicionadas diafásicamente y que, además, expresan distintos valores semánticos: dove, ove, donde y onde (vid. supra, § 1).

Por último, queremos señalar los desplazamientos semánticos que presentan en la actualidad las construcciones con adverbios relativos de lugar en las distintas lenguas contempladas en el trabajo. Entre ellos destacan en todas las lenguas los valores de tiempo, continuativo, anafórico-relativo causal, causal y condicional (vid. supra, $\S 3.3)^{31}$.

30 Recordamos que en español el adverbio adonde $(<a+$ donde $)$ agrupa el mayor número de ejemplos con sentido direccional (vid. supra, Tabla 2).

31 Los dos últimos sentidos no locativos citados, causal y condicional, no han sido documentados en nuestro cor- 
Considerando, en fin, la diacronía de los adverbios relativos planteada someramente al inicio de este trabajo (vid. supra, $\S 1, \S 3.1$ ), que nos revela la tendencia del sistema a la simplificación de formas, y partiendo de algunos trabajos que han recogido el estudio de adverbios relativos y su evolución (Corominas-Pascual 1980: s. v. donde; Azofra 2009: 169; Rey 1992: s. v. où; González Santolalla 2012: 72-75), creemos que esta situación de confluencia en el uso de algunas formas adverbiales relativas -formas con preposición vs. formas sin preposición-se traducirá probablemente con el paso del tiempo en una alteración de la nómina de los adverbios relativos de lugar en lenguas como el italiano -posible pérdida de ove y onde-y un mayor refuerzo gramatical en francés gracias a la presencia de preposiciones que precedan al adverbio relativo de lugar -incremento en el uso de grupos como par où, pour où-.

\section{Referencias bibliográficas}

\section{Fuentes primarias}

Cervantes, Miguel de (1605): El ingenioso hidalgo don Quijote de la Mancha. Adaptación de Andrés Trapiello, 2015. Madrid: Destino.

Cervantes, Miguel de (1605): L'Ingénieux Hidalgo don Quichotte de la Manche. Traducción de Aline Schulman, 1997. París: Seuil.

Cervantes, Miguel de (1605): Don Chisciotte della Mancia. Traducción de Alfredo Giannini, 2007. Milán: Bur: RCS Libri.

\section{Fuentes secundarias}

Alvar, Manuel y Bernard Pottier (1983): Morfología histórica del español. Madrid: Gredos. Azofra Sierra, M. ${ }^{a}$ Elena (2009): Morfosintaxis histórica del español: de la teoría a la práctica. Madrid: UNED.

Battaglia, Giovanni (1974): Grammatica italiana para estudiantes de habla española (8. ${ }^{\mathrm{a}}$ ed.). Roma: Bonacci Editore.

Bello, Andrés ([1847]/2002): Gramática de la lengua castellana destinada al uso de los americanos (ed. digital a partir de Obras completas. Tomo Cuarto (3. ${ }^{\text {a }}$ ed.). Caracas: La Casa de Bello, 1995). Alicante: Biblioteca Virtual Miguel de Cervantes.

Calero Calero, Francisco (2003): Sintaxis latina. Madrid: UNED.

Cano Aguilar, Rafael (1981): Estructuras sintácticas transitivas en el español actual. Madrid: Gredos.

Cantera, Jesús y Eugenio de Vicente ([1986]/2003): Gramática francesa (4. ${ }^{a}$ ed.). Madrid: Cátedra. Corominas Joan y José A. Pascual. (1980). Diccionario crítico etimológico castellano e hispánico. Madrid: Gredos.

Cuervo, Rufino José ([1886-1893]/1953-1954): Diccionario de construcción y régimen de la lengua castellana. Santafé de Bogotá: Instituto Caro y Cuervo.

Dardano, Maurizio y Pietro Trifone (1985): La lingua italiana. Bolonia: Zanichelli.

De Carolis, Maria Teresa (2014): Carriera di un criminale (e-book). Edizioni Imperium.

De Mauro, Tullio (2000): Il Nuovo dizionario della lingua italiana De Mauro. Turín: Paravia. 
[Citado como De Mauro]

Dubois, Jean (1965): Grammaire structurale du français: nom et pronom. París: Librairie Larousse.

Duro, Aldo (1986): Vocabolario della Lingua Italiana Treccani, Roma: Instituto dell'Enciclopedia Italiana. [Citado como Treccani]

Fernández Ramírez, Salvador (1987): Gramática española. 3.2. El pronombre (2. a ed.). Madrid: Arco Libros.

Gabrielli, Aldo (2011): Grande Dizionario Italiano. Milán: Hoepli.

Garzanzi Linguistica (2017): Dizionari Garzanti Linguistica. Milán: De Agostini Scuola.

Gili Gaya, Samuel ([1943]/1980): Curso superior de sintaxis española (13. ${ }^{a}$ ed.). Barcelona: Vox.

González Santolalla, Míriam (2012): Evolución en el tratamiento de los adverbios relativos de lugar: donde, adonde $y$ a donde: confluencias y límites (Trabajo Final de Máster). Madrid: UNED.

Hadermann, Pascale (1993): Étude morphosyntaxique du mot où. París: Duculot.

Hanse, Joseph (1983): Nouveau dictionnaire des difficultés du français moderne. París: Duculot.

Kany, Charles E. (1976): Sintaxis hispanoamericana. Madrid: Gredos.

Llovera Majem, Camilo (1956): Gramática italiana del siglo XX. Barcelona: Bosch.

Martínez, José A. (1989): El pronombre. II. Numerales, Indefinidos y Relativos. Madrid: Arco Libros.

Pinkster, Harm (1995): Sintaxis y semántica del latín. 1. ${ }^{a}$ ed. Madrid: Ediciones Clásicas.

Pruñonosa-Tomás, Manuel (1990): De la cláusula relativa: los relativos donde y cuando. Valencia: Universidad de Valencia.

Real Academia Española. Banco de datos (CREA) [en línea]: Corpus de referencia del español actual. En línea: http://www.rae.es [fecha de consulta: 19-04-2016].

Real Academia Española y Asociación de Academias de la Lengua Española (2005): Diccionario panhispánico de dudas. Madrid: Santillana, 2005. [citado como DPD]

Real Academia Española y Asociación de Academias de la Lengua Española (2009). Nueva Gramática de la Lengua Española. Madrid: Espasa. [citado como NGLE]

Real Academia Española y Asociación de Academias de la Lengua Española (2010). Ortografía de la lengua española. Madrid: Espasa.

Real Academia Española y Asociación de Academias de la Lengua Española (2014). Diccionario de la lengua española (23. ${ }^{\mathrm{a}}$ ed.). Madrid: Espasa. [citado como DLE]

Rey, Alain (dir.) (1992) : Dictionnaire historique de la langue française. París: Le Robert.

Rey-Debove, Josette y Alain Rey (1993) : Le nouveau Petit Robert: Dictionnaire alphabétique et analogique de la langue française. París: Le Robert.

Rubio, Lisardo (1995): Nueva sintaxis latina simplificada. Madrid: Ediciones Clásicas.

Sabatini, Francesco y Vittorio Coletti (dir.) (2011): Dizionario della Lingua Italiana. Milán: RCS Libri.

Sánchez Salor, Eustaquio (1993): Semántica y sintaxis. La oración compuesta latina. Salamanca: Universidad de Extremadura.

Sandfeld, Kristian (1965): Syntaxe du français contemporain: Les propositions subordonnées. Génova: Librairie Droz.

Seco, Manuel (1986): Diccionario de dudas y dificultades de la lengua española. Madrid: Espasa-Calpe.

Seco, Manuel (2011): Nuevo diccionario de dudas y dificultades de la lengua española. Barcelona: Espasa. 
Serianni, Luca (1989): Grammatica italiana: italiano comune e lingua letteraria. Turín: UTET Universitá.

Serianni, Luca (1995): Appunti di grammatica storica italiana (5. ${ }^{\text {a }}$ ed.). Roma: Bulzoni Editore.

Tekavčić, Pavao (1980): Grammatica storica dell'italiano: Morfosintassi (vol. II). Bolonia: il Mulino. 